\title{
ESTABELECENDO UM DIÁLOGO ENTRE APRENDIZAGEM ORGANIZACIONAL, APRENDIZAGEM EMPREENDEDORA E AÇÃO EMPREENDEDORA
}

\author{
Ana Cristina Ferreira ${ }^{1}$ \\ Rita De Cássia Arantes ${ }^{1}$ \\ Mônica Carvalho Alves Cappelle ${ }^{1}$
}

${ }^{1}$ Universidade Federal de Lavras / DAE (Departamento de Administração e Economia) 


\title{
ESTABELECENDO UM DIÁLOGO ENTRE APRENDIZAGEM ORGANIZACIONAL, APRENDIZAGEM EMPREENDEDORA E AÇÃO EMPREENDEDORA
}

\begin{abstract}
Resumo: Com este ensaio teórico objetivou-se apresentar possíveis associações entre as escolas de pensamento da aprendizagem organizacional, rotuladas como individual-cognitivopsicológica e coletiva-sócio-política-cultural, e a aprendizagem empreendedora. A partir dessas associações, buscou-se também alguma relação entre aprendizagem empreendedora e ação empreendedora. Por meio das relações propostas, acredita-se que a partir dos diferentes enfoques das escolas de pensamento da aprendizagem organizacional, a aprendizagem empreendedora surge como elo para construir relações entre o individual e o coletivo, por meio de processos experiencial, gerencial, estratégico e contextual. Portanto, este ensaio permite constatar a possibilidade de relação entre as temáticas, muito embora deva ser compreendido como uma tentativa reflexiva e conceitual que visa explorar alguns aspectos destas temáticas, sem a pretensão de exaurir essa discussão.
\end{abstract}

Palavras-chave: Aprendizagem Organizacional. Aprendizagem Empreendedora. Ação Empreendedora.

\section{Introdução}

O tema 'Aprendizagem Organizacional' tem sido amplamente pesquisado pela área de Estudos Organizacionais nos últimos anos. Inclusive, muitos pesquisadores se propõem a analisar o que tem sido publicado acerca desse tema, contudo, ainda existem lacunas e discussões inacabadas (ANTONELLO; GODOY, 2009). Nogueira e Odelius (2015) afirmam que inexiste uma "teoria da aprendizagem organizacional" capaz de servir de base para novas pesquisas, com pressupostos, premissas e hipóteses testáveis diante das evidências. Entretanto, Antonello e Godoy (2009) alegam que a falta de consenso na conceituação de aprendizagem organizacional é compreensível, e que é "normal" apresentar perspectivas divergentes, considerando-se que não há somente um mundo objetivo a ser descoberto. Assim posto, acredita-se que essa pluralidade de perspectivas é salutar e enriquecedora para o debate sobre aprendizagem.

Existem desafios a serem superados pela aprendizagem organizacional, visto que ela é um fenômeno multidimensional, um processo que atravessa os limites organizacionais e que afeta as pessoas e interage com eles. Além disso, a aprendizagem organizacional é um tópico que perpassa diversas disciplinas e é multinível - constatada nos níveis de indivíduo, grupo e organizacional e interorganizacional (NOGUEIRA; ODELIUS, 2015) - o que aumenta ainda mais esses desafios.

\section{Organizadores:}

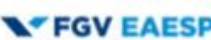

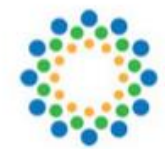
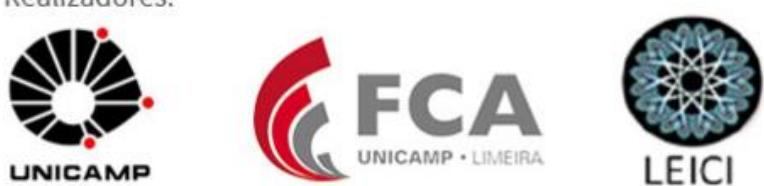
Assim como Antonello (2005), Takahashi e Fischer (2009) afirmam que a aprendizagem vem se tornando um conceito essencial para a compreensão de como as organizações evoluem ao longo do tempo e se adaptam a ambientes de mudança permanente. Nogueira e Odelius (2015) acreditam que para sobreviver e prosperar, as empresas terão de aprender em ritmo cada vez maior. Assim, a construção do conhecimento vigente em uma organização ocorre com base na memória coletiva organizacional, mediante adaptações progressivas de novas ideias ou propostas, compartilhando os seus pressupostos e experiências (RUAS; ANTONELLO, 2003).

Como a aprendizagem organizacional perpassa diversas áreas e é multifacetada e interdisciplinar, ela pode alinhar-se com outros campos do conhecimento, como a temática da aprendizagem empreendedora, dado que, ao perceber como e quando aprendizagem do empreendedor ocorre, podem desencadear novos insights para a investigação do fenômeno em si. O conceito de aprendizagem empreendedora não é único, entretanto pode ser compreendido como um processo dinâmico, reflexivo e socialmente integrado, envolvendo o ato de reconhecer e agir em relação as oportunidades (COPE, 2005; RAE; 2005; MAN, 2006). As relações derivadas das interações entre aprendizagem organizacional e aprendizagem empreendedora, podem oferecer outras possibilidades de se compreender a aprendizagem. Ademais, considerar a aprendizagem com um processo socialmente situado, pode oferecer a possibilidade de explorar questões com lentes mais amplas e mais próximas da realidade organizacional.

Diante destas considerações, faz-se o seguinte questionamento: que (dis)associações podem ser estabelecidas entre as escolas de pensamento da aprendizagem organizacional e a aprendizagem empreendedora? Existe relação entre ação empreendedora e aprendizagem empreendedora?

Logo, objetiva-se com este ensaio teórico apresentar possíveis associações entre as escolas de pensamento da aprendizagem organizacional rotuladas como individual-cognitivopsicológica e coletiva-sócio-política-cultural e a aprendizagem empreendedora e, a partir dessas associações, buscar alguma relação entre aprendizagem empreendedora e ação empreendedora. Acredita-se que a partir dos diferentes enfoques das escolas de pensamento da aprendizagem organizacional, a aprendizagem empreendedora surge como elo para construir relações entre o individual e o coletivo, por meio de processos experiencial, gerencial, estratégico e contextual. Assim como Bitencourt e Azevedo (2006) afirmam, o paradoxo reside no fato de que aspectos aparentemente opostos podem ser complementares, mesmo que não tenham associações.

Este ensaio teórico, deve ser compreendido como uma tentativa reflexiva e conceitual que visa explorar alguns aspectos de grandes temáticas, sem a pretensão de exaurir essa discussão. Assim, a partir do resgate de alguns dos principais autores que influenciam o campo, o trabalho se estrutura na descrição das escolas de pensamento da aprendizagem organizacional, aprendizagem empreendedora e ação empreendedora, para, em seguida, apresentar as possíveis associações entre os temas.

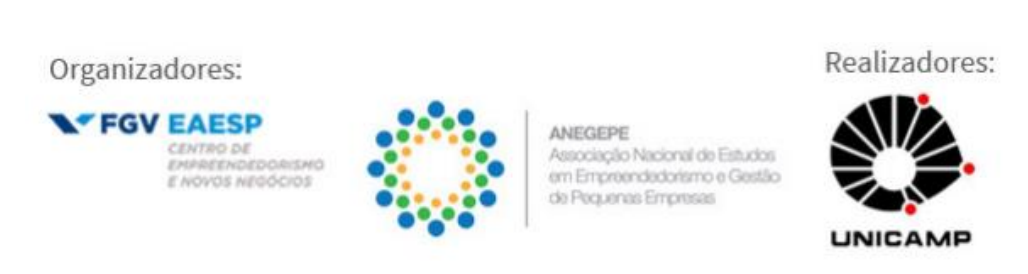




\section{Escolas de Pensamento da Aprendizagem Organizacional}

A aprendizagem no âmbito dos estudos organizacionais é tratada como uma bifurcação: aprendizagem organizacional e organizações que aprendem. A aprendizagem organizacional trata do processo, ou seja, de como as organizações estão aprendendo, assim, seu objetivo é a explicação e compreensão do fenômeno. Já as organizações que aprendem se referem ao atributo, em outras palavras, focam ferramentas para a ação e a prática organizacional para dizer o que as organizações devem fazer para aprender (LOIOLA; BASTOS, 2003).

Loiola e Bastos (2003) afirmam que a aprendizagem organizacional interessa-se pela descrição de como a organização aprende, ou seja, enfoca as habilidades e processos de construção e utilização do conhecimento que podem favorecer a reflexão sobre as possibilidades concretas de ocorrer aprendizagem nesse contexto. Ainda para esses autores, parece existir fortes evidências de que diferenças relativas ao contexto, como pessoas, grupos, setor e local de atuação, são condicionantes que exercem impacto sobre a vivência de aprendizagem de cada organização, considerando-se o fato de que as organizações aprendem de forma diferente. Dessa forma, a aprendizagem organizacional não pode ser reduzida a um "modelo de gestão", mas deve ser compreendida como um conjunto de processos únicos construídos ao longo da vida organizacional, baseado em suas experiências e especificidades (BITENCOURT; AZEVEDO, 2006).

A aprendizagem organizacional, em sua história, foi caracterizada como incremento/melhoria de desempenho no transcorrer do tempo, como fenômeno comportamental, cognitivo, sociocultural, fenômeno com dimensões reflexivas e emocionais, fenômeno experiencial (BITENCOURT; AZEVEDO, 2006). Na administração, a aprendizagem organizacional só passa a ter sentido se associada à mudança, se intencional ou não. Do ponto de vista da teoria sobre mudança organizacional, os processos de aprendizagem podem unir diferentes níveis de análise: individual, grupal e organizacional (RUAS; ANTONELLO, 2003).

A aprendizagem organizacional pode ser considerada também como processo de mudança no estado do conhecimento que é armazenado em parte nos indivíduos, na forma de experiências e competências e também com registros formais. Assim, para nutrir processos de aprendizagem é preciso compreender como a aprendizagem ocorre no local de trabalho (RUAS; ANTONELLO, 2003).

Contudo, a aprendizagem não se refere unicamente a adaptações, e, dessa forma, Nogueira e Odelius (2015) apresentam a distinção entre adaptação organizacional e aprendizagem organizacional com base em Fiol e Lyles (1985), em que esses autores propuseram que a adaptação organizacional refere-se à mudança comportamental como a habilidade de fazer ajustes incrementais como resultado de uma adequação ao ambiente, aos objetivos e às políticas. Já a aprendizagem organizacional envolve não apenas a mudança comportamental, mas, também, as mudanças cognitivas.

Além desta distinção, Nogueira e Odelius (2015) apresentam os quatro processos que ajudam a explicar como a aprendizagem se desenvolve, com base em Crossan, Lane e White (1999): intuição, interpretação, integração e institucionalização (4I's). A intuição (nível individual) é o processo consciente de reconhecimento a partir da experiência pessoal. A
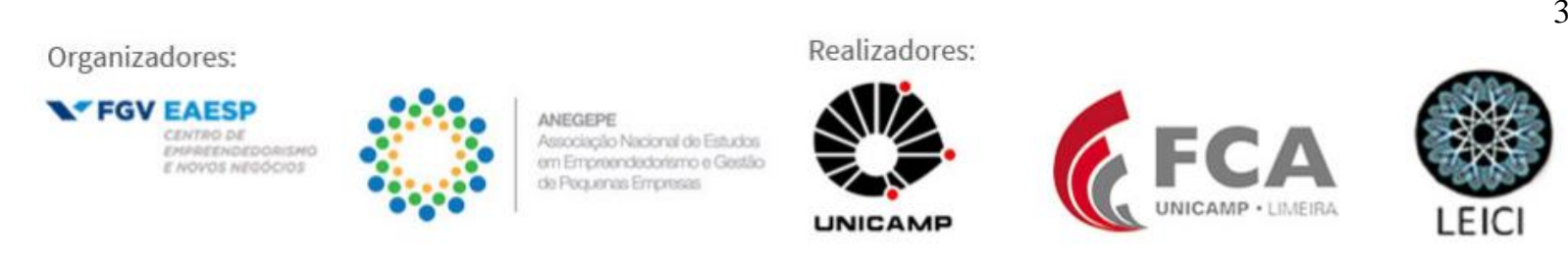
interpretação é o processo de verbalização de intuições mentais do indivíduo. A integração (processo que conecta o grupo ao nível organizacional) é o processo de desenvolvimento compartilhado de sentido entre indivíduos para ação coletiva de modo coordenada. Por fim, a institucionalização é o processo de incorporação da aprendizagem do indivíduo ou do grupo na organização.

Porém, o que se percebe é a pouca atenção conferida ao nível microorganizacional e às interações dos indivíduos nos pequenos grupos por parte dos pesquisadores, em que a imensa maioria dos artigos é desenvolvida em nível de organização (macroprocessos) e muito pouca atenção é despendida aos microprocessos de aprendizagem. Nesse sentido, Loiola e Bastos (2003) apontam que, especialmente no contexto das relações de grupos, um dos problemas centrais da aprendizagem organizacional é compreender como se dá a articulação ou a passagem de processo que é essencialmente individual para o nível coletivo. O processo de aprendizagem individual tem, portanto, impacto mobilizador no conceito e nas práticas de aprendizagem organizacional (RUAS; ANTONELLO, 2003). Para muitos, é a tendência à valorização de um indivíduo pleno que decide, aprimora-se, é criativo e repleto de potencial que leva ao reconhecimento dos processos de aprendizagem como valiosos para a compreensão e a gestão das organizações (BITENCOURT; AZEVEDO, 2006).

Bitencourt e Azevedo (2006) apontam que a literatura indica basicamente três níveis de aprendizagem nas organizações: o individual, o coletivo e o organizacional. Mas estes autores questionam: Como estabelecer o limite entre esses níveis? Como resposta, afirmam que o ponto principal é compreender as diversas relações entre eles e não definir limites. Bitencourt e Azevedo (2006, p. 111) alegam "que muitas vezes esses níveis se sobrepõem e se influenciam mútua e dinamicamente, pois os processos de aprendizagem são construídos e elaborados a partir de interações, o que destaca uma relação de não linearidade entre eles".

Antonello e Godoy (2010) apresentam várias perspectivas de âmbito individual e coletivo, como será descrito mais adiante, e também expõem a perspectiva da ciência administrativa para a aprendizagem organizacional. Com base no estudo de Pawlowsky (2001), que classifica a aprendizagem organizacional em cinco perspectivas teóricas, as autoras acrescentam a sexta perspectiva que seria a da estratégia gerencial. O Quadro 01 apresenta as seis perspectivas, bem como suas definições.

\begin{tabular}{|c|c|}
\hline Perspectivas & Definições \\
\hline $\begin{array}{l}\text { Perspectiva Cognitiva e do } \\
\text { conhecimento }\end{array}$ & $\begin{array}{l}\text { Conhecimento é acumulado de modo consciente, e o processo de } \\
\text { aprendizagem irá incluir, dessa maneira, a aquisição e disseminação da } \\
\text { informação e interpretação será de modo compartilhada. }\end{array}$ \\
\hline $\begin{array}{lcr}\begin{array}{l}\text { Perspectiva } \\
\text { decisão }\end{array} & \text { organizacional } & \text { e } \\
\text { adaptação } & & \\
\end{array}$ & $\begin{array}{l}\text { No decorrer do tempo, as organizações exibem comportamento adaptável, } \\
\text { usando os indivíduos da organização como instrumentos. }\end{array}$ \\
\hline $\begin{array}{l}\text { Perspectiva das teorias de } \\
\text { sistemas }\end{array}$ & $\begin{array}{l}\text { Define a organização como sistemas de atividades coordenadas } \\
\text { conscientemente, de modo que a aprendizagem organizacional é concebida } \\
\text { como um incremento na solução de problemas de sistemas sociais. }\end{array}$ \\
\hline Perspectiva Cultural & A cultura é a aprendizagem comum compartilhada e produzida. \\
\hline Perspectiva na ação & $\begin{array}{l}\text { É inspirada na aprendizagem que ocorre a partir da experiência } \\
\text { (aprendizagem experiencial), e essa experiência dos aprendizes é refletida } \\
\text { enquanto ocorre a ação. }\end{array}$ \\
\hline
\end{tabular}


Perspectiva

estratégia/gerencial da

Considera que a aprendizagem não somente significa que uma organização aprende, mas deve aprender mais rapidamente que outras, como questão de competitividade.

Quadro 01: Perspectivas teóricas da aprendizagem organizacional.

Fonte: Elaborado com base em Pawlowsky (2001) e Antonello e Godoy (2010)

Em suma, fica visível o caráter interdisciplinar da aprendizagem organizacional. Bitencourt (2001), como apresentado por Takahashi e Fischer (2009), adota uma abordagem interdisciplinar para destacar os processos de construção e utilização do conhecimento: processo (em termos de continuidade), transformação (baseada na mudança de atitude), grupo (enfatizando o coletivo), criação e reflexão (sob a ótica da inovação e da conscientização) e ação (apropriação e disseminação do conhecimento, tendo como referência uma visão pragmática). Por isso, a seguir trata-se das principais abordagens nos níveis individual e coletivo.

Para Kim (1998), a aprendizagem individual ocorre a partir da experiência, da observação e da capacidade do indivíduo em avaliar uma situação por meio de reflexões, gerando estruturas cognitivas, modelos interpretativos e rotinas pessoais de trabalho. Probst e Buchel (1997) consideram a aprendizagem individual como produto da reflexão de cada pessoa que muda suas estruturas cognitivas e seus comportamentos.

No nível individual, de acordo com Antonello e Godoy (2010), existem duas visões sobre a relação entre a aprendizagem organizacional e a aprendizagem em psicologia: a primeira, para compreender o processo de aprendizagem organizacional, deve-se usar o conhecimento sobre processos de aprendizagem individual; e na segunda, a aprendizagem individual é a base para a aprendizagem organizacional.

Dentro da perspectiva psicológica, existem várias lógicas para explicar a aprendizagem individual, como a comportamental, em que as organizações aprendem, codificando inferências a partir da sua história e das rotinas que guiam o comportamento delas. Essa perspectiva se apoia nos conceitos da psicologia da cognição e na noção psicodinâmica de que toda a aprendizagem é influenciada pelo passado. Logo, é importante considerar a trajetória já que esta envolve a noção de que a aprendizagem futura construída sobre a aprendizagem acumulada e as capacidades obtidas no passado são importantes para a compreensão da aprendizagem organizacional (ANTONELLO; GODOY, 2010). Tem-se ainda a psicologia aplicada, em que Antonello e Godoy (2010) afirmam que tem muito da teoria da aprendizagem na ação que faz parte do modelo de aprendizagem experiencial de Kolb (1984).

No âmbito coletivo, Antonello e Godoy (2010) apresentam, dentro da perspectiva psicológica, a construção social (perspectiva da psicologia sociocultural), que considera os processos cognitivos socialmente intercedidos pela interpretação, em que a aprendizagem é socialmente construída e fundamentada em situações reais, nas quais as pessoas participam e interagem umas com as outras, ou seja, se considera o coletivo.

Ainda se tratando da coletividade, Antonello e Godoy (2010) apresentam a perspectiva sociológica que sugere que a aprendizagem está integrada no cotidiano da vida dos indivíduos, e que oriunda da fonte informal das relações sociais. A perspectiva antropológica também é abordada pelas autoras, que apresentam a antropologia como referência à aprendizagem que o indivíduo realiza em contexto de estruturas sociais. Nesse
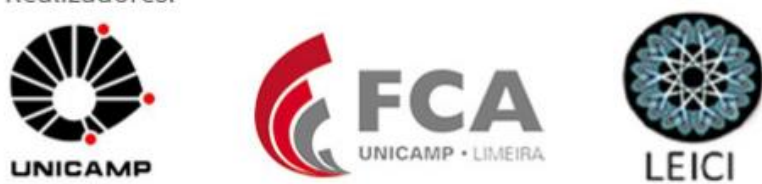
caso, a natureza e o processo da aprendizagem podem variar em culturas e situações diferentes. A perspectiva histórica também é importante ao considerar que as organizações podem usar da sua história para ampliar o potencial de seu conhecimento coletivo armazenado, sem, contudo, cair na obsolescência que pode ocorrer com a aderência rígida às práticas e procedimentos passados.

Outra abordagem que se faz relevante é a perspectiva da ciência política que traz a aprendizagem como processo político no qual os atores investem esforços para influenciar uns aos outros, interpretar a experiência e tentar construir alianças internas. Por fim, na perspectiva econômica a aprendizagem é definida como a aquisição e uso do conhecimento existente e/ou a criação de novo conhecimento com o propósito de melhorar o desempenho econômico (a economia de inovação e a teoria da firma) (ANTONELLO; GODOY, 2010).

Como a aprendizagem organizacional perpassa diversas áreas, ela pode alinhar-se com outros campos do conhecimento, como a temática da aprendizagem empreendedora, que é tratada no próximo tópico.

\section{Aprendizagem Empreendedora}

A aprendizagem empreendedora, tal qual as múltiplas perspectivas acerca da aprendizagem organizacional, desperta o interesse de pesquisadores que buscam investigar como se constitui a aprendizagem, bem como os aspectos inerentes a ela. Com efeito, o próprio conceito de aprendizagem empreendedora não é único. Rae e Carswell (2000) definem essa aprendizagem como sendo um processo social e constante de aprendizagem individual, em que os indivíduos aprendem com suas experiências próprias e com as experiências de seus pares, além disso, formam suas teorias pessoais, as quais serão disseminadas, interpretadas e incrementadas pelos demais em decorrência do seu desempenho.

Conforme Minniti e Bygrave (2001), a aprendizagem empreendedora consiste em um processo que contempla as experiências passadas e a experimentação dos empreendedores. Esses elementos possibilitam ao empreendedor um acesso ao conhecimento acumulado, podendo dessa forma, melhor seu desempenho. Segundo Rae (2005), a aprendizagem empreendedora se traduz no reconhecimento e ação das oportunidades, integrando-se no âmbito social visando iniciar, organizar, e gerir novos empreendimentos. Outra concepção acerca da aprendizagem empreendedora, refere-se a de Politis (2005), que a entende com um processo de aprendizagem experiencial, ou seja, um processo pelo qual as pessoas obtêm, assimilam e organizam os conhecimentos formados em estruturas pré-existentes. Corroborando, Cope (2005) caracteriza a aprendizagem empreendedora com um processo dinâmico e reflexivo, envolvendo aplicação e associação daquele conhecimento adquirido.

Segundo Man (2006), a aprendizagem empreendedora é composta por três enfoques teóricos, a saber: experiencial, cognitivo e networking. A perspectiva experiencial é ancorada no modelo de Kolb (1984) que apresenta a aprendizagem com um processo no qual os conceitos originaram-se e são aperfeiçoados de maneira constante pela atividade reflexiva e experiência do empreendedor. A abordagem cognitiva, por sua vez, considera que a aprendizagem empreendedora consiste em um processo mental de aquisição, estruturação e
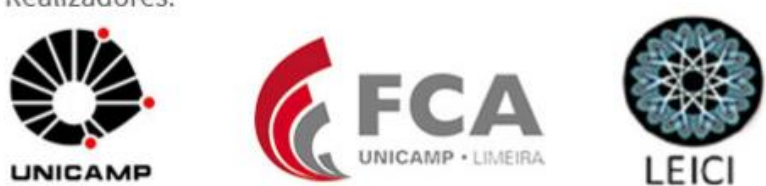
uso do conhecimento empreendedor no longo prazo. As atitudes individuais, os fatores motivacionais e de personalidade podem afetar esse processo. Por fim, a abordagem de networking, direciona-se para as habilidades e conhecimentos adquiridos pelos empreendedores estão vinculados aos relacionamentos sociais desses atores, os quais podem estar associados a relações internas ou externas da organização.

Além disso, Holcamb et al. (2009) apontam outra forma de aprendizagem empreendedora que está relacionada ao modo vicarious learning. Em outras palavras, ela se estabelece por meio da observação da experiência dos outros. Assim, o empreendedor modifica as rotinas ou estratégias organizacionais em resposta ao comportamento de outra empresa (SRINIVASAN; HAUNSCHILD; GREWAL, 2007).

Pode-se considerar também outra maneira pela qual a aprendizagem empreendedora se manifesta: a formal. A aprendizagem formal compõe um tipo de aprendizagem estruturada e focada principalmente na sala-de-aula, em que se tem ações direcionadas ao treinamento e até à avaliação do aprendizado (MARSICK; WATKINS, 2001; MANUTI et al., 2015).

Diante do exposto, a aprendizagem empreendedora pode ser compreendida como sendo um processo pelo qual os indivíduos aprendem a reconhecer e agir sobre oportunidades, por meio da aquisição de novos conhecimentos, da experiência direta e da observação do comportamento e resultado das ações de outros (RAE; CARSWELL, 2000; RAE, 2004; POLITIS, 2005; HOLCOMB et al., 2009). Dessa forma, "a aprendizagem empreendedora é impulsionada por necessidades práticas" (MAN, 2006, p. 315).

Considerando todos os aspectos que perpassam a aprendizagem empreendedora, alguns autores (MORAES; HOELTGEBAUN, 2003; RAE, 2004; POLITIS, 2005) buscaram explorar essas questões por meio de modelos que oferecem a possiblidade de entender a aprendizagem empreendedora e seus enfoques. O foco que central do modelo de Moraes e Hoeltgebaum (2003) está na ideia de que a aprendizagem empreendedora deve ser compreendida em etapas as quais devem ser associadas com o ciclo de vida da própria organização do empreendedor. Assim, torna-se necessário entender como os empreendedores gerenciam seus negócios, bem como conhecer como eles traçam suas estratégias.

O modelo de Rae (2004), por sua vez, concebe o indivíduo dentro do seu contexto social e contempla três dimensões: a) formação pessoal e social; b) aprendizagem contextual; c) empreendimento negociado. Em suma, o modelo mostra as múltiplas relações e os desdobramentos da aprendizagem empreendedora e sua relação com identidade empreendedora, práticas sociais emergentes e as negociações.

Já o modelo de Politis (2005) evidencia a aprendizagem empreendedora como um processo de transformação de experiência em conhecimento. Por meio do modelo, a autora mostra que a experiência anterior em criação de negócios revela-se importante para a aprendizagem empreendedora, visto que os conhecimentos derivados dessas experiências influenciam as futuras escolhas estratégicas dos empreendedores em seus novos empreendimentos.

Em síntese, esses modelos contribuem para a investigação da aprendizagem empreendedora e os elementos que a compõe. Torna-se pertinente considerar alguns aspectos convergentes nesses modelos, os quais estão relacionados principalmente com a abordagem experiencial, baseada na prática, na ação e contexto, e em entender como o conhecimento é obtido. Além disso, os autores também corroboram quanto a importância de se considerar nas
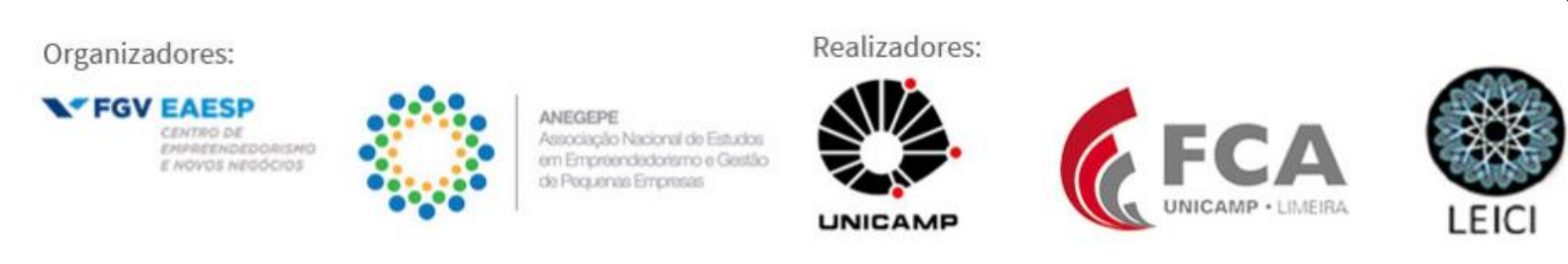
pesquisas a trajetória dos empreendedores, bem como suas experiências e motivações (ZAMPIER; TAKAHASHI, 2011). Nesse sentido, o próximo tópico trata da ação empreendedora, suas abordagens e características.

\section{Ação Empreendedora}

Entre as abordagens que constituem o campo conceitual do empreendedorismo, em geral, as correntes mais disseminadas são aquelas que consideram o empreendedor como um agente "principal", seja ele um sujeito impulsionador da inovação ou um agente que apresenta certas características que o fazem um ser "especial". Essas visões representam as abordagens econômica e comportamental respectivamente. Apesar de conceber o empreendedorismo e o empreendedor de maneiras distintas, cada qual com seus princípios e seus pressupostos, essas abordagens se tangenciam no foco que é dado ao indivíduo (GOMES; LIMA; CAPPELLE, 2013).

Nesse sentido, há uma tentativa relativamente nova que visa descolar o foco do agente empreendedor para a função empreendedora, com o intuito de preencher as lacunas presentes nas abordagens econômica e comportamental. Assim, baseado na concepção da construção social da realidade (PAIVA JÚNIOR, 2004), o empreendedor está em uma construção contínua e conjunta da realidade como o próprio aprimoramento. Dessa forma, o ato intencional do empreendedor será descolado para os outros. Destarte, a ação empreendedora amplia as lentes acerca do empreendedor e do empreendedorismo e pode ser considerada um conceito multidimensional, visto que atua de maneira dialógica envolvendo empresa, empreendedor e o ambiente (PAIVA JÚNIOR, 2004).

Observa-se, na literatura, que a ação empreendedora é tema pouco explorado, entretanto, as concepções existentes retratam o caráter coletivo presente na ação empreendedora. Bractnicky (2005) caracteriza o indivíduo empreendedor como aquele que realiza a ação empreendedora. Assim, tais ações correspondem ao núcleo central do empreendedorismo e são resultantes da interação entre ambiente e a organização, reconciliando oportunidades e ações.

McMullen e Shepperd (2006) também compartilham dessa visão, abordando que o bom desempenho da economia estaria atrelado a percepção de oportunidades por empreendedores, com ênfase na ação e não na figura do agente. Alvarez e Barney (2007) representam outra corrente acerca dessa ação. Na perspectiva proposta pelos autores, procurase reconhecer ações em relação às oportunidades, e assim, não haveria busca de oportunidades, existiria, ao contrário, ações empreendedoras que representam construções sociais. Nesse mesmo sentido, Klein (2008) menciona que o foco deve estar na ação empreendedora e que as oportunidades são resultantes dessas ações, assim, as oportunidades são manifestações dessas ações.

Buscando estabelecer uma teoria sobre a ação empreendedora, Berlung (2005, p. 2) menciona que "ação é frequentemente definida como um comportamento ou atividade que carrega um sentido subjetivo para o agente, isto é, fazer algo com um grau de intencionalidade ou atenção". De acordo com o autor, a ação empreendedora consiste em uma prática situada, e permite, ao mesmo tempo, compreender o empreendedor como sujeito reflexivo e

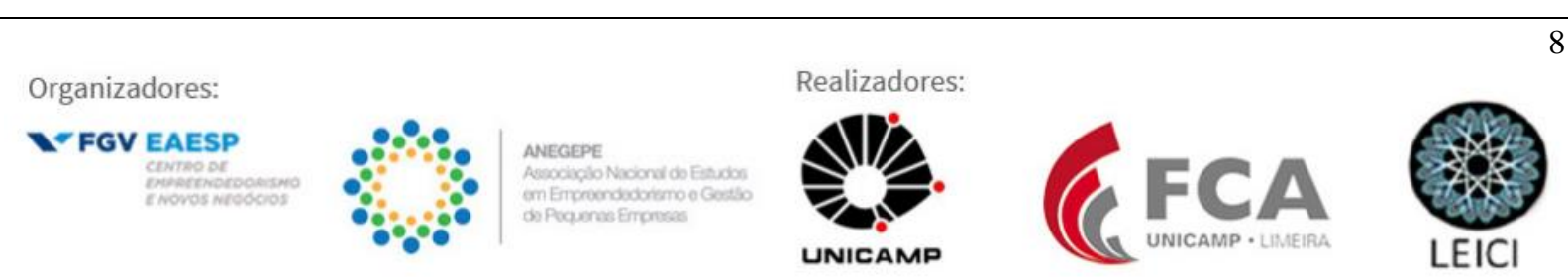


estrategicamente situado. Nesse sentido, para Watson (2013), o empreendedorismo é um tipo de ação empreendedora, e ele se constitui na ação, associando sua concepção de ação social a uma ação humana diferenciada.

Assim, a noção de ação empreendedora, possibilita compreender o empreendedorismo em uma perspectiva coletiva, na qual todas as pessoas, de forma individual ou coletiva, podem praticar uma ação empreendedora, seja ela radical ou incremental (GOMES; LIMA; CAPPELLE, 2013). Além disso, conforme Andrade, Lima e Borges (2014), as ações empreendedoras podem ser consideradas com um fenômeno presente em todas as organizações, independentemente de sua finalidade, podendo ser identificadas nas construções de oportunidade, nos processos de transformação de relações dos agentes sociais e na promoção da consolidação dessas transformações nas relações externas da organização.

Diante das considerações acerca da aprendizagem organizacional, aprendizagem empreendedora e ação empreendedora, o próximo tópico apresentas as convergências entre as temáticas, bem como as implicações de tais associações.

\section{Interpretando As (Dis)Associações}

O estudo de Gartner (1985) representa um marco para o campo do empreendedorismo. Esse estudo destaca-se por apontar uma nova lente de compreensão para o fenômeno. Nesta nova concepção, o empreendedorismo não deve ser reduzindo à sua função econômica, pelo contrário, se deve considerá-lo como um fenômeno composto de variáveis complexas, a saber: indivíduo, organização, ambiente socioeconômico e processo, e tipos de ações dos indivíduos.

Em contrapartida, ao ampliar as concepções acerca do empreendedorismo, são demandadas abordagens conceituais que se direcionem para compreender sobre os aspectos que perpassam o campo, bem como investigar as relações entre as variáveis, visto que os resultados provenientes podem oferecer outras possibilidades de análise para o fenômeno em questão. Nesse sentido, perceber como e quando a aprendizagem do empreendedor ocorre, podem desencadear novos insights para a investigação do fenômeno em si. Além disso, a aprendizagem organizacional é multinível, e estabelece relações entre os níveis de indivíduo, grupal e organizacional, também retratados pela abordagem que concebe o empreendedorismo como fenômeno social.

Nessa concepção, Wang e Chug (2014) argumentam que aprendizagem empreendedora é um importante conceito que teve sua gênese na interface entre empreendedorismo e aprendizagem organizacional. Estas duas temáticas apresentam-se imbricadas e permitem traçar pontos convergentes.

A concepção de aprendizagem nas teorias baseadas em práticas concebe a aprendizagem como um processo social, no qual as relações e interações dos indivíduos são elementos sociais e materiais de contextos específicos. Assim, a aprendizagem como um processo abrange tensões e fluidez dentro do contexto (ANTONELLO; GODOY, 2009).

Corroborando, cabe salientar que o processo de aprendizagem, como explanado, não se configura como elementar, visto que contempla em sua essência uma interface entre o individual e coletivo. Tratando especificamente dos empreendedores, essa superposição dos
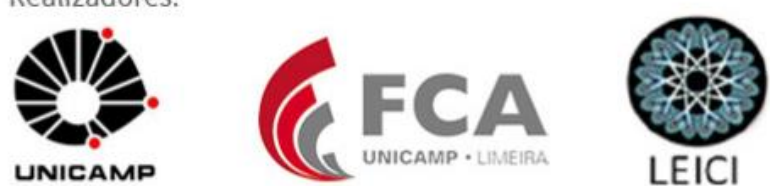
níveis de análise é ainda mais evidente, dado que esses empreendedores, em determinados contextos e considerando suas características pessoais, aprendem a respeito de uma totalidade de assuntos, com as mais diversas pessoas, sejam elas clientes, fornecedores, concorrentes, ou ainda, outros empreendedores. Assim, os empreendedores aprendem com a sua própria experiência, seja ela passada ou aquela adquirida com o fazer, de fato (LÉVESQUE; MINNITI; SHEPHERD, 2009).

Nesse sentido, torna-se possível conceber que o aprendizado, tanto na aprendizagem organizacional quanto na aprendizagem empreendedora, é internalizado por meio de replicações e experimentação de atividades, as quais poderão proporcionar ao indivíduo a identificação de oportunidades (RAVASI; TURATI, 2003).

Nessa mesma linha, Cope $(2005,2011)$ menciona que para analisar criticamente suas percepções e suposições, incluindo suas ações, é preciso que o empreendedor busque uma reflexão intensa e própria como meio de impactar a eficácia de seus negócios. Considerando o empreendedorismo sob ótica da abordagem dinâmica de aprendizagem, os empreendedores aprendem durante a criação e gestão de empreendimentos, além de apreender sobre si mesmos e sobre gestão de forma geral.

Considerando o foco da aprendizagem empreendedora no nível macro, a principal diferença entre a aprendizagem coletiva e individual está em sua natureza. A aprendizagem coletiva é cumulativa, pública e interativa, e depende da eficácia dos relacionamentos do empreendedor (CAPELLO, 1999). Ademais, observa-se que o processo de aprendizagem entre organização e indivíduos ocorre à medida que as organizações armazenam conhecimentos em suas políticas, regras e diretrizes. Ao acumular tal conhecimentos, a organização aprende com seus membros, e os indivíduos, de forma similar, são socializados a partir das crenças institucionais. São estes processos que possibilitam ao empreendedor atuarem como "agentes de aprendizagem" para ponderar o cenário organizacional como um todo, identificando oportunidades latentes, traçando estratégias deliberadas, reunindo recursos e outros (CROSSAN et al., 1999 apud WANG; CHUG, 2014).

Tratando especificamente da aprendizagem em nível micro, Politis (2005), em seu modelo, salienta que o conhecimento do empreendedor abrange três dimensões: o apreender, o reconhecer oportunidades e o saber agir em seus novos empreendimentos. Entretanto, a experiência, por si só, não produz conhecimento. É pertinente compreender que, ao considerar a aprendizagem empreendedora como um processo sociopsicológico, o empreendedor aprende por meio de questionamentos e reflexões advindos de uma nova situação ou um novo ambiente, os quais permitirão ao empreendedor a possibilidade de examinar e refletir sobre aquela situação, e, portanto, um novo conhecimento é gerado (WANG; CHUG, 2014).

Nesse contexto, as oportunidades identificadas possuem uma relação estreita com a ação empreendedora. Para alguns autores, as oportunidades são responsáveis por desencadear as ações empreendedoras. Em contrapartida, para outros autores, as oportunidades são resultantes das ações empreendedoras (ANDRADE; LIMA; BORGES, 2014). Embora haja essa divergência entre os pesquisadores, considera-se que as oportunidades são centrais tanto na identificação e ações sobre elas, como em sua criação. Assim, as criações de oportunidades vistas como construções sociais não existem sem a percepção do empreendedor.

Nessa perspectiva, as novas oportunidades criadas resultam de ações empreendedoras combinadas com as novas ações, que devem ser criadas e interpretadas pelos agentes

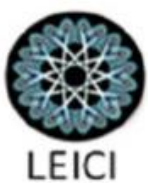


organizacionais, evidenciando a ação empreendedora como núcleo do fenômeno social do empreendedorismo, englobando indivíduos, organização e o ambiente socioeconômico (ANDRADE; LIMA; BORGES, 2014). A Figura 01 sintetiza das relações.

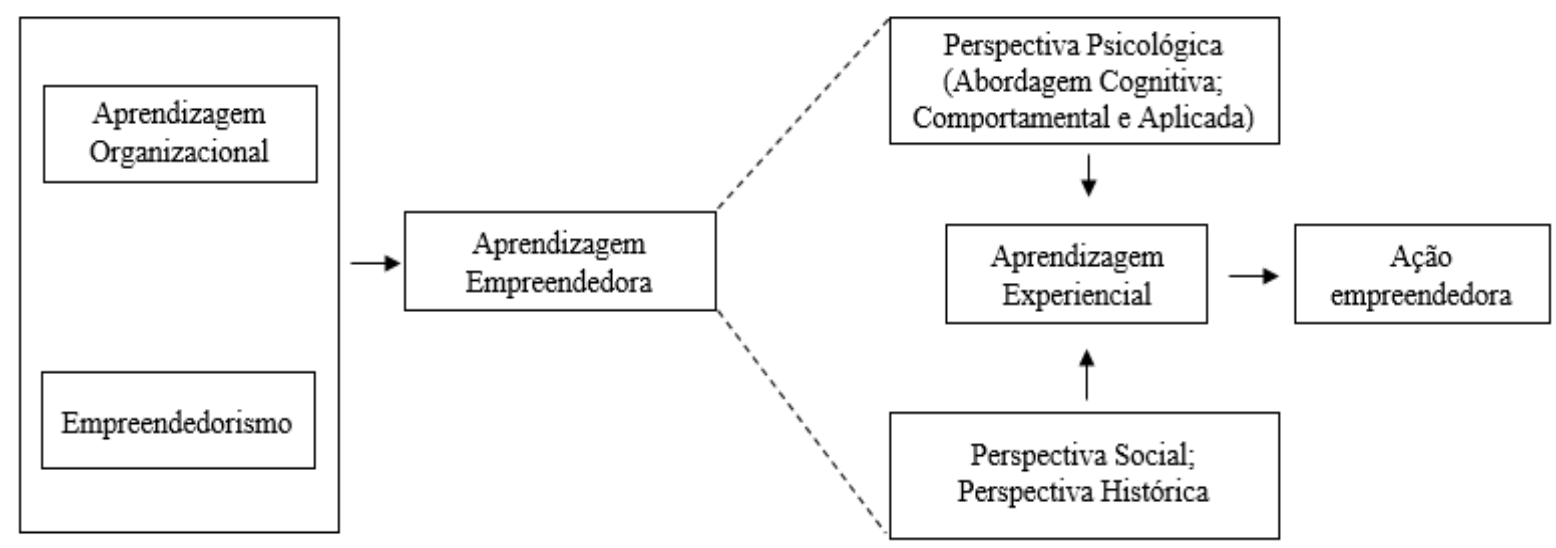

Figura 01: Aprendizagem organizacional, aprendizagem empreendedora e ação empreendedora. Fonte: Elaboração própria.

A aprendizagem empreendedora advém da interação da aprendizagem organizacional e do empreendedorismo e pode ser entendida tanto do nível macro (principalmente pelas perspectivas social e histórica) e micro (especialmente pela perspectiva psicológica). Essas dimensões coletiva e individual são influenciadoras da aprendizagem experiencial (que é um dos enfoques da aprendizagem empreendedora), visto que a aprendizagem pela experiência não significa qualquer aprendizado, mas sim àquele advindo de ações permeadas por reflexões. Logo, pela aprendizagem experiencial é possível identificar oportunidades que resultam de ações empreendedoras com apreensão das relações sociais que permeiam as práticas empreendedoras e gerenciais. Por exemplo, uma empresa por meio de mecanismo de gestão do conhecimento pode influenciar a aprendizagem experiencial por intermédio das interações entre os indivíduos e pela mobilização dos próprios saberes, viabilizando a transformação de oportunidades em ações empreendedoras.

Pelas próprias conceituações de aprendizagem organizacional e aprendizagem empreendedora, é possível constatar a semelhança destas abordagens, principalmente no sentido de serem consideradas processo e envolverem mudanças. Essas mudanças, quando referentes a aprendizagem organizacional, se ligam ao estado do conhecimento gerado e mudanças cognitivas. A aprendizagem empreendedora envolve o processo social e constante de aprendizagem individual, que contempla as experiências passadas e a experimentação dos empreendedores, quanto ao acesso ao conhecimento acumulado. Nesse ponto, destacam-se dois aspectos significativos: um referente à perspectiva da psicologia aplicada, no nível individual, ligada à teoria da aprendizagem na ação, em que trata da aprendizagem a partir da experiência (aprendizagem experiencial); por outro lado, no nível coletivo, a perspectiva histórica proporciona o acesso ao conhecimento coletivo acumulado.

Ainda considerando o passado e a história como influenciadores da aprendizagem, pode-se ligar a aprendizagem empreendedora com a perspectiva psicológica da cognição,

\section{Organizadores:}
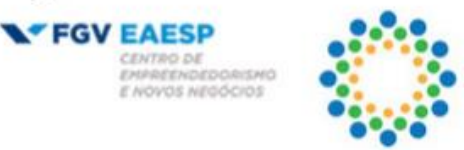

ANEGEPE

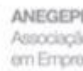

Realizadores:
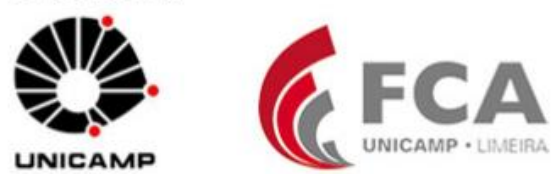

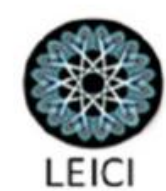


psicodinâmica e comportamental (nível individual), em que a aprendizagem futura é construída pela aprendizagem acumulada.

Aos que acreditam que não deveria existir foco na busca de oportunidades, estes consideram que as ações empreendedoras devem ser vistas como representação das construções sociais. Ou seja, as oportunidades são manifestações dessas ações (a oportunidade pode ser compreendida como objeto da ação), logo o foco deve estar na ação empreendedora. Essas construções sociais, que partem da perspectiva psicológica, consideram que a aprendizagem é socialmente construída e fundamentada em situações reais, na interação entre as pessoas e processos cognitivos de interpretação e reflexão, logo, possibilitam a ação.

Nesse sentido, pode-se estabelecer uma relação entre a ação empreendedora e a aprendizagem empreendedora. Especificamente, em uma das formas de aprendizagem empreendedora: a experiencial. A aprendizagem pela experiência é resultante de uma ação informal em que o indivíduo aprende pelas interações sociais de que participa o que pode ser considerado, de forma concomitante, uma ação empreendedora, pois deve estar fortemente vinculado ao negócio central, além de proporcionar, por meio da aprendizagem, um diferencial competitivo no universo organizacional.

\section{Considerações Finais}

Objetivou-se, com esse ensaio teórico, apresentar possíveis associações entre as escolas de pensamento da aprendizagem organizacional rotuladas como individual-cognitivopsicológica e coletiva-sócio-política-cultural e a aprendizagem empreendedora e, a partir dessas associações, buscar alguma relação entre aprendizagem empreendedora e ação empreendedora. Acredita-se que a partir dos diferentes enfoques das escolas de pensamento da aprendizagem organizacional, a aprendizagem empreendedora surge como elo para construir relações entre o individual e o coletivo, por meio de processos experiencial, gerencial, estratégico e contextual.

A aprendizagem empreendedora envolve o processo social e constante de aprendizagem individual, que contempla as experiências passadas e a experimentação dos empreendedores, quanto ao acesso ao conhecimento acumulado. Além disso, ela advém da interação da aprendizagem organizacional e do empreendedorismo e pode ser entendida tanto do nível macro (principalmente pelas perspectivas social e histórica) e micro (especialmente pela perspectiva psicológica). Essas dimensões coletiva e individual são influenciadoras da aprendizagem experiencial (que é um dos enfoques da aprendizagem empreendedora). Cabe destacar que a aprendizagem pela experiência não significa qualquer aprendizado, mas sim àquele advindo de ações permeadas por reflexões.

Portanto, este ensaio permite constatar a possibilidade de relação entre as temáticas, muito embora deva ser compreendido como uma tentativa reflexiva e conceitual que visa explorar alguns aspectos destas temáticas, sem a pretensão de exaurir essa discussão.

Quanto às limitações na elaboração deste ensaio, destacam-se a dificuldade no aprofundamento de questões relacionadas a ação empreendedora, visto que a literatura deste tema pode ser considerada incipiente. Assim, cada um dos pontos discutidos merece mais atenção e novas discussões aprofundadas.
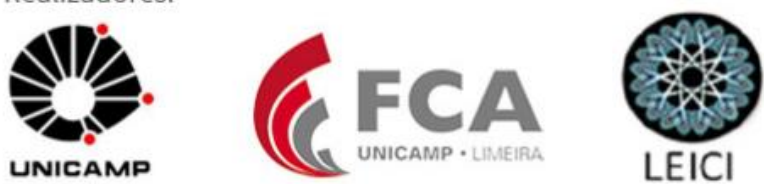


\section{Referências}

ALVAREZ, S. A.; BARNEY, J. B. Discovery and creation: alternative theories of entrepreneurial action. Organizações em contexto, ano 3, n. 6, dez. 2007.

NOGUEIRA, R. A.; ODELIUS, C. C. Desafios da pesquisa em aprendizagem organizacional. Cadernos EBAPE. BR, v. 13, n. 1, 2015.

ANDRADE, D. M.; LIMA, J. B. de; BORGES, A. F. Ações Empreendedoras em Empresas Familiares: Um Estudo sob a Ótica de Oportunidades, Inovação e Aprendizagem. In: VIII EGEPE - Encontro de Estudos sobre Empreendedorismo e Gestão de Pequenas Empresas, 2014, Goiânia. Anais... Goiânia: Egepe, 2014. p. 1 - 17.

ANTONELLO, C. S.; GODOY, A. S. Uma agenda brasileira para os estudos em aprendizagem organizacional. RAE-Revista de Administração de Empresas, v. 49, n. 3, 2009.

ANTONELLO, C. S.; GODOY, A. S. A encruzilhada da aprendizagem organizacional: uma visão multiparadigmática. RAC - Revista de Administração Contemporânea, v. 14, n. 2, 2010.

BITENCOURT, C. C; AZEVEDO, D. O futuro da aprendizagem organizacional: possibilidades e desafios. Revista de Administração de Empresas, v. 46, n. SPE, p. 110$112,2006$.

CAPELLO, R. Spatial transfer of knowledge in high technology milieux: learning versus collective learning processes. Regional Studies, 33, pp. 353-365. 1999

COPE, J. Toward a dynamic learning perspective of entrepreneurship. Entrepreneurship Theory and Practice, 29, pp. 373-397. 2005

COPE, J.; WATTS, G. Learning by doing - an exploration of experience, critical incidents and reflection in entrepreneurial learning, International Journal of Entrepreneurial Behavior \& Research, v. 6, n.3, p.104 - 124. 2000.

GARTNER, W. B. Conceptual Framework for Describing the Phenomenon of New Venture Creation. The Academy of Management Review. Vol. 10, No. 4. pp. 696-706, 1985.

GOMES, A. F. LIMA, J. B.; CAPPELLE, M. C. A. Do empreendedorismo à noção de ações empreendedoras: reflexões teóricas. Revista Alcance - Eletrônica, Vol. 20 - n. 02- p. 203-220 - abr/jun. 2013.

HOLCOMB, T. R.; IRELAND, R. D.; HOLMES Jr, R. M.; HITT, M. A. Architecture of entrepreneurial learning: exploring the link among heuristics, knowledge, and action. Entrepreneurship Theory and Practice, v. 33, n. 1 p. 167-192, jan. 2009

KIM, D. H. O elo entre aprendizagem individual e organizacional. In: KLEIN, D. A gestão estratégica do capital intelectual: recursos para a economia baseada no conhecimento. Rio de Janeiro: Qualitymark, 1998. p.61-92.

KLEIN, P. Opportunity discovery, entrepreneurial action and economic organization. Strategic Entrepreneurship Journal, v. 2, p. 175-190, 2008. 
LÉVESQUE, M.; MINNITI, M. SHEPHERD, D. Entrepreneurs' decisions on timing of entry: learning from participation and from the experiences of others. Entrepreneurship Theory and Practice, 33, pp. 547-570. 2009

LOIOLA, E.; BASTOS, A. V. B. A produção acadêmica sobre aprendizagem organizacional no Brasil. Revista de Administração Contemporânea, v. 7, n. 3, p. 181-201, 2003.

MAN, T. W. Y. Exploring the behavioural patterns of entrepreneurial learning: a competency approach. Education Training, v. 48, n. 5, p. 309 - 321, 2006.

MANUTI, A.; PASTORE, S.; SCARDIGNO, A. F.; GIANCASPRO, M. L.; MORCIANO, D. Formal and informal learning in the workplace: a research review. International Journal of Training and Development, v. 19, n. 1, p. 1-17, 2015.

MARSICK, V. J.; WATKINS, K. E. Informal and incidental learning. New Directions for Adult and Continuing Education, v. 1 n. 89, p. 25-34, 2001.

McMULLEN, J. S.; SHEPPERD, D. A. Entrepreneurial action and the role of incertainity in the theory of the entrepreneur. Academy of Management Review, v. 31, n. 1, p. 132-152, 2006.

MINNITI, M.; BYGRAVE, W. A dynamic model of entrepreneurial learning. Entrepreneurship Theory and Practice, v. 25, n. 3, p. 5-16, 2001.

MORAES, L. V. S.; HOELTGEBAUM, M. Um modelo para a análise do processo de aprendizagem de empreendedores. In: Third International Conference of the Iberoamerican Academy of Management, 2003, São Paulo, Anais... São Paulo: 2003.

PAIVA JÚNIOR, F. G. de. O empreendedorismo na ação de empreender: uma análise sob o enfoque da fenomenologia sociológica de Alfred Schütz. 2004. 369 p. Tese (Doutorado em Administração) - Universidade Federal de Minas Gerais, Belo Horizonte, 2004.

POLITIS, D. The process of entrepreneurial learning: a conceptual framework. Entrepreneurship Theory and Practice, v. 29, n. 3, p. 399-424, jul. 2005.

PROBST, G. J. B.; BÜCHEL, B. S. Organizational Learning. UK: Prentice Hall, 1997.

RAE, D. Entrepreneurial learning: a practical model from the creative industries. Education Training, v. 46, n. 8/9, p. 492-500, 2004.

RAE, D.; CARSWELL, M. Using a life-story approach in researching entrepreneurial learning: the development of a conceptual model and its implications in the design of learning experiences. Education + Training, v. 42, n. 4/5, p. 220-228, 2000.

RAVASI, D. TURATI, C. Exploring entrepreneurial learning: a comparative study of technology development projects. Journal of Business Venturing, 20, pp. 137-164. 2005.

RUAS, R.; ANTONELLO, C. S. Repensando os referenciais analíticos em aprendizagem organizacional: uma alternativa para análise multidimensional. Revista de Administração Contemporânea, v. 7, n. 3, p. 203-212, 2003. 
SRINIVASAN, R.; HAUNSCHILD, P.; GREWAL, R. Vicarious learning in new product introductions in the early years of a converging market. Management Science, v. 53, n. 1, p. 16-28, jan. 2007.

WANG, C. L.; CHUGH, H. Entrepreneurial learning: past research and future challenges. International Journal of Management Reviews, v. 16, n. 1, p. 24-61, 2014.

WATSON, T. J. Entrepreneurial action and the Euro-American social tradition: paragmatin, realism and looking beyond the "entrepreneur". Entrepreneurship \& Regional Development, v.25, n.1-2,p. 16- 33, 2013.

TAKAHASHI, A. R. W.; FISCHER, A. L. Debates passados, presentes e futuros da aprendizagem organizacional-um estudo comparativo entre a produção acadêmica nacional e internacional. RAM. Revista de Administração Mackenzie, v. 10, n. 5, 2009.

ZAMPIER, M. A.; TAKAHASHI, A. R. W. Competências empreendedoras e processos de aprendizagem empreendedora: modelo conceitual de pesquisa. Cadernos EBAPE.BR, v. 9, n. Ed. Especial, art. 6, p. 564-585, 2011. 